\title{
High malaria parasitemia among outpatient febrile children in low endemic area, East-Central Tanzania in 2013
}

\author{
Beatrice Chipwaza ${ }^{1,2^{*}}$ and Robert D. Sumaye ${ }^{2}$
}

\begin{abstract}
Objective: This study investigated the prevalence and distribution patterns of malaria in Kilosa district as part of non-malaria causes of febrile illnesses in children study. We enrolled febrile patients aged 2-13 years presenting at the outpatient department during the rainy and dry seasons, in 2013. For each participant, we tested for malaria parasites and identified parasite species using microscopy. We then calculated parasite density and estimated geometric mean parasite density.

Results: The overall malaria prevalence in febrile children was $23.7 \%(n=609)$. Plasmodium falciparum accounted for 98.6\% of malaria positives. There was a heterogeneous distribution of malaria cases among the 17 wards constituting the catchment area. A high proportion $(69.4 \%, n=144)$ of malaria positive individuals had high parasite densities. Individuals who were enrolled in the rainy season had higher geometric mean parasite density (15415.1 parasites/ $\mu$, 95\% Cl 10735.3-22134.9) compared to the dry season (6115.3 parasites/ $\mu \mathrm{l}, 95 \% \mathrm{Cl}$ 4237.8-8824.6). The relatively high malaria prevalence recorded in Kilosa, an area considered low endemicity, calls for concerted effort in documenting malaria burden at fine geographical scales and tailor preventive and control strategies that target hotspots of high malaria transmission.
\end{abstract}

Keywords: Malaria, Parasite density, Children, Kilosa district, Tanzania

\section{Introduction}

Despite the continued efforts geared to reduce malaria case incidence and death rates, malaria remains a major disease, especially in children. The 2018 World malaria report estimates about 219 million malaria cases occurred in 2017 which is an increase of about 3.5 million cases compared to 2016 [1], and accounts for about 435,000 annual mortalities. Importantly, the majority of these cases occur in Sub-Saharan Africa where after every 2 min a child dies from malaria. In Tanzania, malaria is endemic in most parts of the country and over $90 \%$ of the population lives in areas where malaria is

\footnotetext{
*Correspondence: bchipwaza@sfuchas.ac.tz; bchipwaza@ihi.or.tz

2 Ifakara Health Institute, Ifakara, P.O. Box 53, Ifakara, Tanzania

Full list of author information is available at the end of the article
}

endemic. Malaria accounts for over $30 \%$ of the national disease burden and is the major cause of hospital attendance, admission and death where it accounts for about 16 million clinical cases and over 100,000 deaths annually [2].

Diverse malaria control efforts have been implemented for several years in malaria-endemic areas. However, we have been observing rises and falls in malaria cases and deaths globally and Tanzania. The 2015 World malaria report shows a global decrease from about 262 million cases in 2000 to 213 million in 2015 and the decline in malaria deaths by $48 \%$ [3]. Similarly in Tanzania, the overall prevalence of malaria among children age 6-59 months has declined from $17.7 \%$ in 2008 to $9.2 \%$ in 2012 [4] and 7\% in 2017 [5]. 
There are variations in the malaria burden between regions and districts of Tanzania. This includes differences in entomological inoculation rates, vector composition, and transmission intensities at districts level or even within villages [6-9]. Malaria prevalence ranges from as low as $<1 \%$ in Zanzibar archipelago to about $27 \%$ in the Western zone [10] with a higher burden in rural compared to urban areas [5]. Based on these variations, regular updates of malaria morbidities in different settings are invaluable. Understanding the status of malaria prevalence in different localities will allow for better planning of control strategies. This study aimed to investigate malaria prevalence among children who attend the outpatient department of Kilosa district hospital, as part of a study on non-malaria causes of febrile illnesses.

\section{Main text \\ Methods \\ Study site and population}

This study was conducted at Kilosa district hospital in the Morogoro region, Tanzania for 6 months covering both the rainy and dry seasons in 2013, as part of a large study on non-malaria causes of febrile illnesses in children $[11,12]$. Kilosa district experiences the main rainy season between March-May and dry season from JuneOctober. The main economic activities are crop production and livestock keeping. The district is divided into 38 wards and 164 villages [13]. In 2012, the population of Kilosa district was 438,175 people, in which the number of children aged 2-13 years was 146,891 [14]. The participants enrolled in the study came from 17 out of 38 wards, with the inhabitants in this catchment area accounting for about half of the district population. There were 71 healthcare facilities, of which 3 are hospitals, 7 health centers, and 61 dispensaries. The district hospital serves as a referral hospital for primary healthcare facilities (dispensaries and health centers) but also patients who directly seek treatment at the hospital. Malaria has been accounting for more than half (55.5\%) of outpatient visits and is the leading cause of deaths in children $<5$ years. In the year 2012 over one-fifth of deaths were caused by malaria [15].

\section{Inclusion criteria, participants enrolment and procedures}

The study participants were patients presenting at the outpatient department (OPD), aged 2-13 years and with axillary body temperature $\geq 37.5{ }^{\circ} \mathrm{C}$. For 6 months each working day (excluding weekends) the study team enrolled 5 participants who met inclusion criteria, agreed to participate and the parent/guardian provided written informed consent. For each participating child, a standardized questionnaire was administered to the parent/guardian to capture demographic and clinical information. The management of patients was performed according to the local standard of care based on world health organization (WHO) and Ministry of Health guidelines [16, 17], and the same information was also recorded in the standardized questionnaire.

\section{Diagnosis of malaria}

A thick and thin blood smears were prepared from a finger prick blood sample and stained with 3\% Giemsa solution, and examined under a light microscope with oil immersion. These were used for the identification and quantification of the malaria parasite respectively. A smear was considered negative if no parasites were seen after viewing at $100 \times$ high-power fields. For quality assurance, each slide was read independently by a second microscopist and any discrepancies were resolved by a third microscopist. The parasite density was determined according to the number of parasites per 200 white blood cells (WBC) counts, assuming a total WBC count of $8000 / \mu \mathrm{L}[18]$.

\section{Parasitaemia case definitions}

Parasitaemia was categorized as low $(<1000$ parasites $/ \mu \mathrm{l}$ blood), moderate (1000-4999 parasites/ $\mu$ l blood), high (5000-99,999 parasites/ $\mu$ l blood), and hyperparasitaemia ( $\geq 100,000$ parasites/ $\mu$ l blood) [19-21]. Fever was classified as mild if the temperature was $37.5-38.3^{\circ} \mathrm{C}$, moderate at $38.4-39.4{ }^{\circ} \mathrm{C}$ and high at $39.5^{\circ} \mathrm{C}$.

\section{Data management and analysis}

Data were entered into an Access database, verified and cleaned to ensure that clinical data and laboratory findings are matched. The statistical analyses were performed using STATA software (version 13; Stata Corp., TX USA). The geometrical mean of parasite density (GMPD) was calculated as the antilogarithm of the arithmetic mean of the base 10 logarithms of 10 plus the parasite density. Pearson's Chi Square test was used to determine the association between categorical variables. An alpha level of 0.05 was used for all tests of statistical significance.

\section{Results}

\section{Demographic characteristics}

A total of 609 participants were enrolled, of these $51.2 \%$ $(\mathrm{n}=312)$ were males and $48.8 \%(\mathrm{n}=297)$ females. Among the 609 participants, 354 (58.1\%) were children < 5 years and 255 (41.9\%) had $\geq 5$ years. About $50 \%$ (310) of patients were enrolled during the dry season while 299 (49.1\%) were enrolled in the rainy season. During the time of enrollment, the majority of the participants (78\%) had a mild fever. Overall 177 (29.9\%; $n=609)$ had prior treatment and $154(25.3 \% ; n=609)$ of those with prior treatment were treated with antimalaria drugs. Only 29 
$(4.8 \% ; n=609)$ of those treated with antimalaria drugs were later diagnosed with malaria.

\section{Malaria prevalence and distribution}

The overall malaria prevalence was $23.7 \%(\mathrm{n}=609)$ and Plasmodium falciparum accounted for $98.6 \%$. Two patients $(1.4 \%)$ had a mixed infection with $P$. falciparum and $P$. malariae. There was no difference in malaria prevalence by season, sex and age groups,
Table 1. There was a heterogeneous distribution of malaria within the wards. Out of the 144 malaria positive patients, the highest prevalence $(31-50 \%)$ was recorded from individuals living in six wards i.e. Kimamba A, Masanze, Kidete, Magomeni, Mabwerebwere and Rudewa as indicated in Fig. 1, while the prevalence was $21-30 \%$ in individuals from six wards i.e. Mabwerebwere, Rudewa, Zombo, Kilangali, Chanzuru, and Ulaya.

Table 1 Malaria prevalence and geometric mean parasite density (GMPD) stratified by sex, age group, and season

\begin{tabular}{|c|c|c|c|c|c|}
\hline Variable & Category & Malaria prevalence (n) & GMPD (per $\mu \mathrm{l})$ & $95 \% \mathrm{Cl}$ & $P$ value \\
\hline Overall & N/A & $23.65 \%(609)$ & 9834.62 & 7539.97-12827.6 & \\
\hline \multirow[t]{2}{*}{ Sex } & Male & $26.28 \%(312)$ & 8618.75 & 5902.98-12583.94 & 0.86 \\
\hline & Female & $20.88 \%(297)$ & 11710.06 & $8101.48-16925.98$ & \\
\hline \multirow[t]{2}{*}{ Age group } & $<5$ years & $24.29 \%(354)$ & 9779.53 & $6777.71-14110.83$ & 0.52 \\
\hline & $\geq 5$ years & $22.75 \%(255)$ & 9916.86 & $6734.94-14602.11$ & \\
\hline \multirow[t]{2}{*}{ Season } & Rainy & $23.87 \%(310)$ & 15415.1 & $10735.33-22134.88$ & 0.0002 \\
\hline & Dry & $23.41 \%(299)$ & 6115.26 & $4237.75-8824.59$ & \\
\hline
\end{tabular}

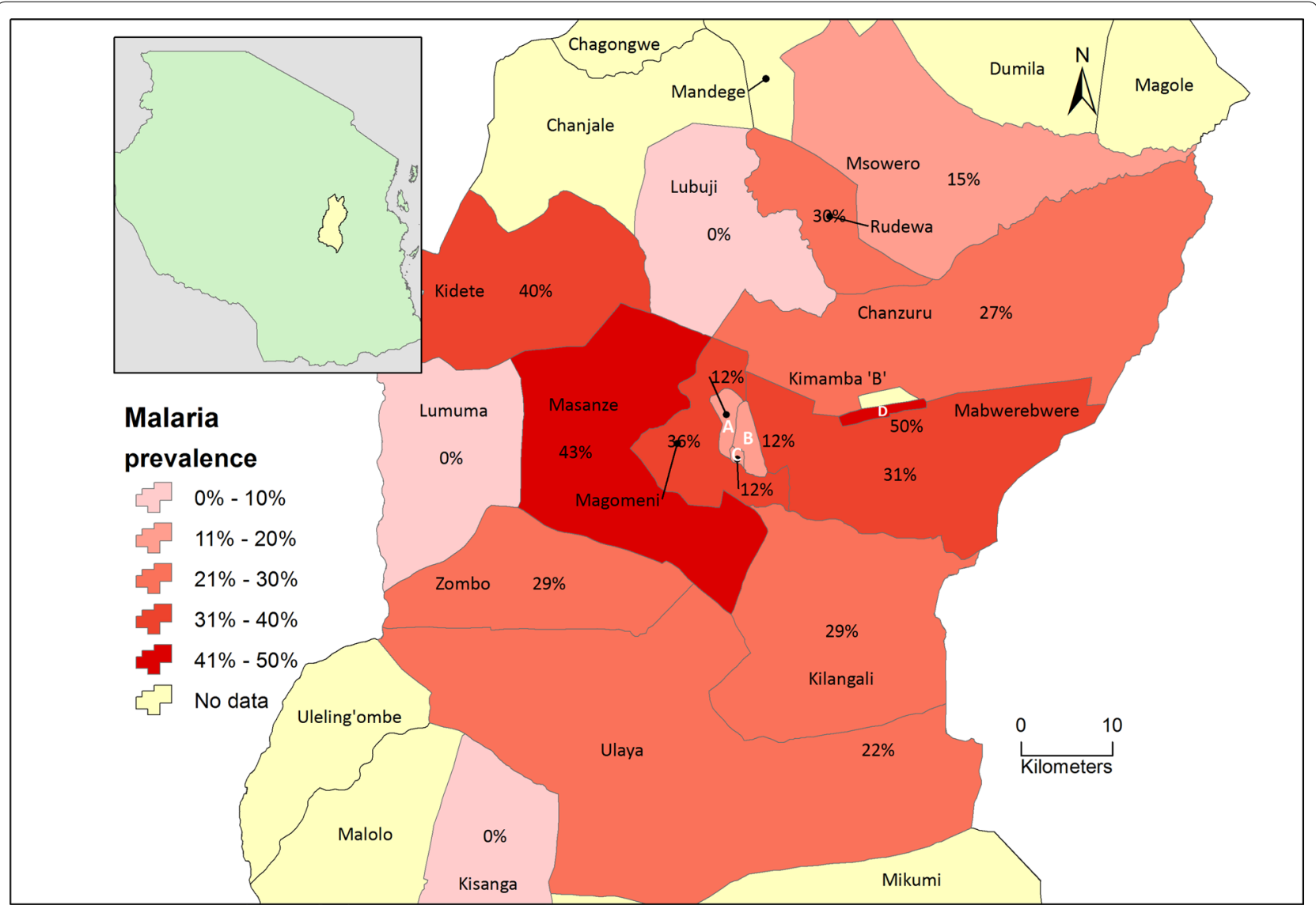

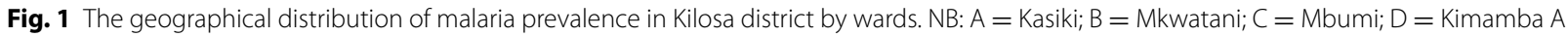




\section{Malaria parasitaemia and parasite density}

A high proportion $(69.4 \%, \mathrm{n}=144)$ of malaria positive individuals had high parasite densities whereas only $2.1 \%$ had hyperparasitaemia, Table 2 . The overall geometric mean parasite density was 9834.6 parasites per $\mu \mathrm{l}$ of blood. The GMPD was significantly higher during the rainy season (15415.1 parasites/ $\mu \mathrm{l}, 95 \%$ CI 10735.322134.9 ) than the dry season (6115.3 parasites $/ \mu \mathrm{l}, 95 \% \mathrm{CI}$ 4237.8-8824.6). There was no difference in GMPD by sex and age groups, Table 1.

\section{Discussion}

We report here high malaria parasitaemia which might imply our study population is sitting at a transmission hotspot in a low prevalence designated Morogoro region. There are relatively few studies in Tanzania reporting parasite density, a report in Muheza [22] had comparable findings with ours, whereas low density among children is reported in other places [23, 24]. In other countries also reports indicate low parasitaemia in a high proportion of children $[25,26]$, however, the high parasite densities recorded during the rainy seasons were comparable with findings from Nigeria [27].

The overall malaria prevalence reported here was higher compared to the data from the 2011-2012 malaria indicator survey (13\%) for the Morogoro region [28], and P. falciparum accounted for $99 \%$ of cases. It is however comparable to data from Kigoma (26\%) and Lindi (26\%) regions in the Western and South-eastern zones respectively, the areas considered having the highest prevalence in Tanzania [28]. In the same catchment area, a 2015 study involving community sampling (random sampling of household members) irrespective of age and fever status reported $17.5 \%$ of malaria prevalence that was still high [29]. These observations suggest the presence of high transmission hotspots despite a sustained overall decline in malaria prevalence in children over time in the Morogoro region. Reports from other parts of Tanzania have revealed a declining prevalence of malaria in children including the Mwanza region (9.5\%), Muheza $(16.4 \%)$ and Korogwe (8.3\%) districts in the year 2014 [30-32].

The prevalence was not different between age groups, sex and seasons. Similar observations were reported in the same district where malaria infection was associated with the age groups of $1-10$ years and $11-20$ years [29]. Our findings are also in agreement with a systematic review indicating an evenly distributed clinical malaria incidence across the first 10 years of life for all transmission scenarios [33]. On the contrary, a study in a neighboring Pwani region reported a slightly higher prevalence in males [34]. This was similar to that reported by the Demographic and Health Survey and Malaria Indicator Survey [10] and other studies in north-east Tanzania [35] and Ethiopia [36]. The observed difference might be contributed by study population characteristics that also included primary healthcare facilities, geo-ecological differences, high exposure behaviour among males and other cultural factors that have been associated with malaria risk [37].

Wards with rice fields and other anthropogenic activities like bricks making had high prevalence $[29,38]$ and had previously been linked with higher entomological inoculation rates and malaria burden reflecting the presence of suitable microhabitats for malaria vectors [39]. The observed distribution might be coincidental as the study design was not powered to capture spatial distribution.

Despite the general decline of malaria cases in endemic areas including Tanzania, pockets of hotspots remain.

Table 2 Malaria parasite density among malaria positive individuals stratified by season, sex, age group, and fever category

\begin{tabular}{|c|c|c|c|c|c|}
\hline \multirow[t]{2}{*}{ Variable } & \multirow[t]{2}{*}{ Level } & \multicolumn{4}{|c|}{ Parasite density } \\
\hline & & Low \% (n) & Moderate $\%(n)$ & High \% (n) & Hyper \% (n) \\
\hline Overall & na & $11.8 \%(17)$ & $16.7 \%(24)$ & $69.4 \%(100)$ & $2.1 \%(3)$ \\
\hline \multirow[t]{2}{*}{ Season } & Dry & $6.9 \%(10)$ & $11.1 \%(16)$ & $30.6 \%(44)$ & $0.0 \%(0)$ \\
\hline & Rainy & $4.9 \%(7)$ & $5.6 \%(8)$ & $38.9 \%(56)$ & $2.1 \%(3)$ \\
\hline \multirow[t]{2}{*}{ Sex } & Female & $3.5 \%(5)$ & $6.3 \%(9)$ & $32.6 \%(47)$ & $0.7 \%(1)$ \\
\hline & Male & $8.3 \%(12)$ & $10.4 \%(15)$ & $36.8 \%(53)$ & $1.4 \%(2)$ \\
\hline \multirow[t]{2}{*}{ Age group } & $<5$ years & $7.6 \%(11)$ & $10.4 \%(15)$ & $39.6 \%(57)$ & $2.1 \%(3)$ \\
\hline & $\geq 5$ years & $4.2 \%(6)$ & $6.3 \%(9)$ & $29.9 \%(43)$ & $0.0 \%(0)$ \\
\hline \multirow[t]{3}{*}{ Fever category } & Mild & $6.9 \%(10)$ & $10.4 \%(15)$ & $45.8 \%(66)$ & $1.4 \%(2)$ \\
\hline & Moderate & $4.9 \%(7)$ & $6.3 \%(9)$ & $19.4 \%(28)$ & $0.7 \%(1)$ \\
\hline & High & $0.0 \%(0)$ & $0.0 \%(0)$ & $4.2 \%(6)$ & $0.0 \%(0)$ \\
\hline
\end{tabular}


Such hotspots are likely maintained by the high parasite density in a section of the population like what we observed in this study. Our findings call for a focused intensification of the preventive and control measures targeting high transmission areas to sustain the gains on malaria infections reductions.

\section{Limitations}

The prevalence of malaria in this study could be underor over-estimated because this study is a hospital-based survey and might not reflect the situation in the primary healthcare facilities and the population at large, however, these findings still provide important information on malaria at fine geographical scale.

\section{Abbreviations}

GMPD: Geometric mean parasite density; OPD: Outpatient department; WBC: White blood cells; WHO: World Health Organization.

\begin{abstract}
Acknowledgements
We would like to acknowledge the district medical officer of Kilosa for allowing us to conduct our study at Kilosa district hospital. We are grateful to the study participants for agreeing to take part in the research. We sincerely acknowledge the medical officer in charge at the hospital for his cooperation throughout the study period. Finally, we thank the study clinician Dr. Justin Saileni and the laboratory technician Catherine Mwegoha of Kilosa district hospital, Sebastian Cobero and Augustino Mahundi of Ifakara Health Institute for their technical expertise in the study.
\end{abstract}

\section{Authors' contributions}

$B C$ designed the study. BC supervised the data collection in the Kilosa district. RDS performed the analysis of data. BC drafted the manuscript and RDS contributed to manuscript preparation. Both authors read and approved the final manuscript.

\section{Funding}

This work was funded by the Tanzania Commission for Science and Technology (COSTECH) and additional funds were provided by Ifakara Health Institute. The funders had no role in study design, data collection, and analysis, decision to publish, or preparation of the manuscript.

\section{Availability of data and materials}

The datasets used and/or analysed during the current study are available from the corresponding author on reasonable request.

\section{Ethics approval and consent to participate}

This study received ethical approval from the Institutional Review Board of the Ifakara Health Institute (IHI/IRB/No: 01-2013) and Medical Research Coordinating Committee of Tanzania's National Institute for Medical Research (NIMR/HQ/R.8a/Vol.1X/1472). Before the start of the study, the participants were explained the objectives, methods, and benefits of the study. Written informed consent was obtained from those who were willing to participate in the study. Also, verbal assent was obtained from children aged 7-12 years children and those aged $>12$ years provided their own written informed assent, accompanied by written consent of a parent or guardian. Confidentiality was assured by using identity number (ID) which was given to each study participant and all specimens, case report forms, and laboratory results forms were marked with the patient ID number, rather than the patient's name.

\section{Consent to publish}

Not applicable.

\section{Competing interests}

The authors declare that they have no competing interests.

\section{Author details}

${ }^{1}$ St Francis University College of Health and Allied Sciences, P.O. Box 175, Ifakara, Tanzania. ${ }^{2}$ Ifakara Health Institute, Ifakara, P.O. Box 53, Ifakara, Tanzania.

Received: 18 February 2020 Accepted: 16 May 2020

Published online: 24 May 2020

\section{References}

1. WHO. World Malaria Report 2017. Geneva: World Health Organization; 2018.

2. PMI. Tanzania Malaria Operational Plan FY 2019. President's Malaria Initiative; 2019.

3. WHO. World Malaria Report 2015. Geneva: World Health Organization; 2015.

4. Mboera LE, Mazigo HD, Rumisha SF, Kramer RA. Towards malaria elimination and its implication for vector control, disease management and livelihoods in Tanzania. Malaria World J. 2013;4:19.

5. MOH. Tanzania Malaria Indicator Survey 2017 Ministry of Health, community development, Gender, Elderly and Children. 2018. .

6. Kaindoa EW, Matowo NS, Ngowo HS, Mkandawile G, Mmbando A, Finda $\mathrm{M}$, et al. Interventions that effectively target Anopheles funestus mosquitoes could significantly improve control of persistent malaria transmission in south-eastern Tanzania. PLoS ONE. 2017;12(5):e0177807.

7. Finda MF, Limwagu AJ, Ngowo HS, Matowo NS, Swai JK, Kaindoa E, et al. Dramatic decreases of malaria transmission intensities in Ifakara, southeastern Tanzania since early 2000s. Malar J. 2018;17(1):362.

8. Das S, Muleba M, Stevenson JC, Pringle JC, Norris DE. Beyond the entomological inoculation rate: characterizing multiple blood feeding behavior and Plasmodium falciparum multiplicity of infection in Anopheles mosquitoes in northern Zambia. Parasit Vectors. 2017;10(1):45.

9. Bousema T, Drakeley C, Gesase S, Hashim R, Magesa S, Mosha F, et al. Identification of hot spots of malaria transmission for targeted malaria control. J Infect Dis. 2010;201(11):1764-74.

10. $\mathrm{MOH}$. Tanzania demographic and health survey and malaria indicator survey 2015-2016-final report. Ministry of Health, Community Development, Gender, Elderly and Children. 2016.

11. Chipwaza B, Mhamphi GG, Ngatunga SD, Selemani M, Amuri M, Mugasa $J P$, et al. Prevalence of bacterial febrile illnesses in children in Kilosa district, Tanzania. PLoS Negl Trop Dis. 2015;9(5):e0003750.

12. Chipwaza B, Mugasa JP, Selemani M, Amuri M, Mosha F, Ngatunga SD, et al. Dengue and chikungunya fever among viral diseases in outpatient febrile children in Kilosa District hospital, Tanzania. PLoS Negl Trop Dis. 2014;8(11):e3335.

13. MRCO. Morogoro region socio-economic profile. Morogoro Regional Commissioner's Office. 2012.

14. NBS. 2012 Population and housing census. Population distribution by administrative areas. Tanzania National Bureau of Statistics http://www. tzdpg.or.tz/fileadmin/documents/dpg_internal/dpg_working_group s_clusters/cluster_2/water/WSDP/Background_information/2012_Censu S_General_Reportpdf.2013.

15. MOH. Midterm analytical review of performance of the health sector strategic plan III 2009-2015. 2015. Ministry of Health, Community Development, Gender, Elderly and Children http://www.who.int/healthinfo/count ry_monitoring_evaluation/TZ_AnalyticalReport_2013pdf Accessed 30 July 20192015.

16. MOH. Standard Treatment Guidelines and Essential Medicines List. Ministry of Health, Community Development, Gender, Elderly and Children. 2013.

17. WHO. WHO Guidelines for the management of febrile illnesses. Geneva: World Health Organization; 2012.

18. Greenwood B, Armstrong J. Comparison of two simple methods for determining malaria parasite density. Trans R Soc Trop Med Hyg. 1991;85(2):186-8.

19. Sumbele IU, Ning TR, Bopda OS, Nkuo-Akenji T. Variation in malariometric and red cell indices in children in the Mount Cameroon area following enhanced malaria control measures: evidence from a repeated crosssectional study. Malar J. 2014;13(1):334.

20. Kimbi HK, Sumbele IU, Nweboh M, Anchang-Kimbi JK, Lum E, Nana Y, et al. Malaria and haematologic parameters of pupils at different altitudes 
along the slope of Mount Cameroon: a cross-sectional study. Malar J. 2013;12(1):193.

21. Koram KA, Owusu-Agyei S, Utz G, Binka FN, Baird JK, Hoffman SL, et al. Severe anemia in young children after high and low malaria transmission seasons in the Kassena-Nankana district of northern Ghana. Am J Trop Med Hyg. 2000;62(6):670-4.

22. Gonçalves BP, Huang C-Y, Morrison R, Holte S, Kabyemela E, Prevots DR, et al. Parasite burden and severity of malaria in Tanzanian children. N Engl J Med. 2014;370(19):1799-808.

23. Mazigo HD, Meza W, Ambrose EE, Kidenya BR, Kweka EJ. Confirmed malaria cases among children under five with fever and history of fever in rural western Tanzania. BMC Res Notes. 2011;4(1):359.

24. Mboera L, Kamugisha M, Rumisha S, Msangeni H, Barongo V, Molteni $F$, et al. The relationship between malaria parasitaemia and availability of healthcare facility in Mpwapwa District, central Tanzania. Tanzania J Health Res. 2006;8(1):22-7.

25. Maina RN, Walsh D, Gaddy C, Hongo G, Waitumbi J, Otieno L, et al. Impact of Plasmodium falciparum infection on haematological parameters in children living in Western Kenya. Malar J. 2010;9(3):S4.

26. Nwaorgu O, Orajaka B. Prevalence of malaria among children 1-10 years old in communities in awka north local government area, Anambra State South East Nigeria. Afr Res Rev. 2011;5(5):264-81.

27. Samdi L, Ajayi J, Oguche S, Ayanlade A. Seasonal variation of malaria parasite density in paediatric population of north eastern Nigeria. Glob J Health Sci. 2012;4(2):103.

28. MOH. 2011-12 HIV/AIDS and Malaria Indicator Survey. Ministry of Health and Social Welfare. 2013.

29. Mazigo HD, Rumisha SF, Chiduo MG, Bwana VM, Mboera LE. Malaria among rice farming communities in Kilangali village, Kilosa district, Central Tanzania: prevalence, intensity and associated factors. Infect Dis Poverty. 2017;6(1):101

30. Mahende C, Ngasala B, Lusingu J, Butichi A, Lushino P, Lemnge M, et al. Aetiology of acute febrile episodes in children attending Korogwe District Hospital in north-eastern Tanzania. PLoS ONE. 2014;9(8):e104197.

31. Msaki BP, Mshana SE, Hokororo A, Mazigo HD, Morona D. Prevalence and predictors of urinary tract infection and severe malaria among febrile children attending Makongoro health centre in Mwanza city, NorthWestern Tanzania. Arch Public Health. 2012;70(1):4.

32. Mtove G, Hendriksen ICE, Amos B, Mrema H, Mandia V, Manjurano A, et al. Treatment guided by rapid diagnostic tests for malaria in Tanzanian children: safety and alternative bacterial diagnoses. Malar J. 2011;10(1):290.

33. Carneiro I, Roca-Feltrer A, Griffin JT, Smith L, Tanner M, Schellenberg JA, et al. Age-patterns of malaria vary with severity, transmission intensity and seasonality in sub-Saharan Africa: a systematic review and pooled analysis. PLoS ONE. 2010;5(2):e8988.

34. Mubi M, Kakoko D, Ngasala B, Premji Z, Peterson S, Björkman A, et al. Malaria diagnosis and treatment practices following introduction of rapid diagnostic tests in Kibaha District, Coast Region, Tanzania. Malar J. 2013;12(1):293.

35. Winskill P, Rowland M, Mtove G, Malima RC, Kirby MJ. Malaria risk factors in north-east Tanzania. Malar J. 2011;10(1):98.

36. Yeshiwondim AK, Gopal S, Hailemariam AT, Dengela DO, Patel HP. Spatial analysis of malaria incidence at the village level in areas with unstable transmission in Ethiopia. Int J Health Geogr. 2009;8(1):5.

37. Bates I, Fenton C, Gruber J, Lalloo D, Lara AM, Squire SB, et al. Vulnerability to malaria, tuberculosis, and HIV/AIDS infection and disease. Part 1: determinants operating at individual and household level. Lancet Infect Dis. 2004;4(5):267-77.

38. Mboera L, Mlozi M, Senkoro K, Rwegoshora R, Rumisha S, Mayala B, et al. Malaria and agriculture in Tanzania: impact of land-use and agricultural practices on malaria burden in Mvomero District. National Institute for Medical Research, Dar es Salaam, Tanzania. 2007

39. Ijumba J, Lindsay S. Impact of irrigation on malaria in Africa: paddies paradox. Med Vet Entomol. 2001;15(1):1-11.

\section{Publisher's Note}

Springer Nature remains neutral with regard to jurisdictional claims in published maps and institutional affiliations.
Ready to submit your research? Choose BMC and benefit from:

- fast, convenient online submission

- thorough peer review by experienced researchers in your field

- rapid publication on acceptance

- support for research data, including large and complex data types

- gold Open Access which fosters wider collaboration and increased citations

- maximum visibility for your research: over $100 \mathrm{M}$ website views per year

At BMC, research is always in progress.

Learn more biomedcentral.com/submissions 